\title{
Using Pre-melted Phase Change Material to Keep Payload Warm without Power for Hours in Space
}

\author{
Michael K. Choi \\ NASA Goddard Space Flight Center, Greenbelt, MD 20771
}

\begin{abstract}
During a payload transition from the transport vehicle to its worksite on the International Space Station (ISS), the payload is unpowered for up to 6 hours. Its radiator(s) will continue to radiate heat to space. It is necessary to make up the heat loss to maintain the payload temperature above the cold survival limit. Typically an interplanetary Probe has no power generation system. It relies on its battery to provide limited power for the Communication and Data Handling (C\&DH) subsystem during cruise, and heater power is unavailable. It is necessary to maintain the C\&DH temperature above the minimum operating limit. This paper presents a novel thermal design concept that utilizes phase change material (PCM) to store thermal energy by melting it before the payload or interplanetary Probe is unpowered. For the ISS, the PCM is melted by heaters just prior to the payload transition from the transport vehicle to its worksite. For an interplanetary Probe, the PCM is melted by heaters just prior to separation from the orbiter. The PCM releases thermal energy to keep the payload warm for several hours after power is cut off.
\end{abstract}

\section{Nomenclature}

$\begin{array}{ll}C & =\text { carbon } \\ C \& D H & =\text { communication and data handling } \\ C C D & =\text { charge coupled device } \\ C O N C & =\text { concentrator } \\ E B & =\text { electronics boxes } \\ E L C & =\text { ExPRESS Logistics Carriers } \\ F P A & =\text { focal plane assembly } \\ H & =\text { hydrogen } \\ \text { IOB } & =\text { instrument optical bench } \\ I S S & =\text { International Space Station } \\ L E O & =\text { low Earth orbit } \\ M L I & =\text { multilayer insulation } \\ \text { NICER } & =\text { Neutron Star Interior Composition Explorer } \\ P C M & =\text { phase change material } \\ P V L P & =\text { Pioneer Venus Large Probe } \\ R H U & =\text { radioisotope heater unit } \\ S / C & =\text { spacecraft } \\ T E C & =\text { thermoelectric cooler }\end{array}$

\section{Introduction}

paylaod could be without power for several hours in space. The first example is that on the International Space Station (ISS). During a payload transition from the transport vehicle to its worksite, the payload is unpowered for up to 6 hours. Generally a payload has one or more thermal radiators to reject its electronics and detector waste heat to space during the science operation mode. When power to the payload is cut off for 6 hours, the radiator(s) will continue to radiate heat to space. It is necessary to make up the heat loss to maintain the payload temperature above the cold survival limit. For example, the cold survival limit for electronics is typically $-30^{\circ} \mathrm{C}$. The second example is a free-flight interplanetary Probe that cruises to a planet, such as Venus, after its separation from the orbiter (mother-ship). The cruise phase could be at least several days long. Pioneer Venus Large Probe (PVLP), for

\footnotetext{
${ }^{*}$ Senior Aerospace Engineer, Heat Transfer, AIAA Associate Fellow.
} 
example, had a 24-day cruise. ${ }^{1}$ Typically an interplanetary Probe has no solar array or other power generation system. It relies on its battery to provide limited power for the Communication and Data Handling (C\&DH) subsystem during cruise, and heater power is unavailable. It will be necessary to maintain the C\&DH components above the minimum operating limit which is typically $-10^{\circ} \mathrm{C}$.

Radioisotope heater units (RHU), which use plutonium 238-dioxide, could provide heat when power is unavailable. But they dissipate heat all the time, and add waste heat during the science mode. It also has other issues, such as safety, large cost increase due to launch site modification, availability of radioisotope supply today and political barrier.

This paper presents an innovative thermal concept to maintain the payload temperature above the cold survival or minimum operating limit without power for several hours in space. It is to add phase change material (PCM) to the payload. For the ISS, the PCM is melted by heaters just prior to payload transition from the transport vehicle to its worksite and when power is available. When power is cut off during the 6-hour transition period, the PCM releases the thermal energy stored in it to make up the heat radiated from the radiator(s) to space. For interplanetary Probes, the PCM is melted by heaters just prior to separation from the orbiter and when power is available. Heater power is supplied by the orbiter electrical power system (e.g. solar arrays). After the Probe separates from the orbiter, the PCM releases the thermal energy stored in it to make up the heat leaked from the payload to the structure, which radiates heat to space, until solar heating stabilizes its temperature.

\section{Objective}

The objective of this paper is to present a novel thermal design concept of using pre-melted PCM to keep payload temperatures above cold survival or minimum operating limits without power for several hours in space.

\section{Paraffin PCM}

Paraffin wax is a good PCM candidate. It has a high latent heat of fusion per unit mass, which is in the 155 to $253 \mathrm{~kJ} / \mathrm{kg}$ range (Fig. 1) ${ }^{2-6}$. It also has a range of melting points (Fig. 2) ${ }^{2-6}$, and is well within typical payload temperature limits. PCM potentially reduces the mass of the payload since latent heat, instead of sensible heat, is used for thermal energy storage. Figure 3 shows a paraffin pack flown on an instrument in the NASA MESSENGER mission to Mercury. Figure 4 shows a paraffin panel built and tested for the NASA Vegetation Canopy Lidar mission. ${ }^{2}$ They were intended to maintain component temperatures stable. Typically the ratio of mass of paraffin to mass of shell is 2:1. ${ }^{5}$ The technology readiness level of paraffin PCM for spaceflight is at least 6 .

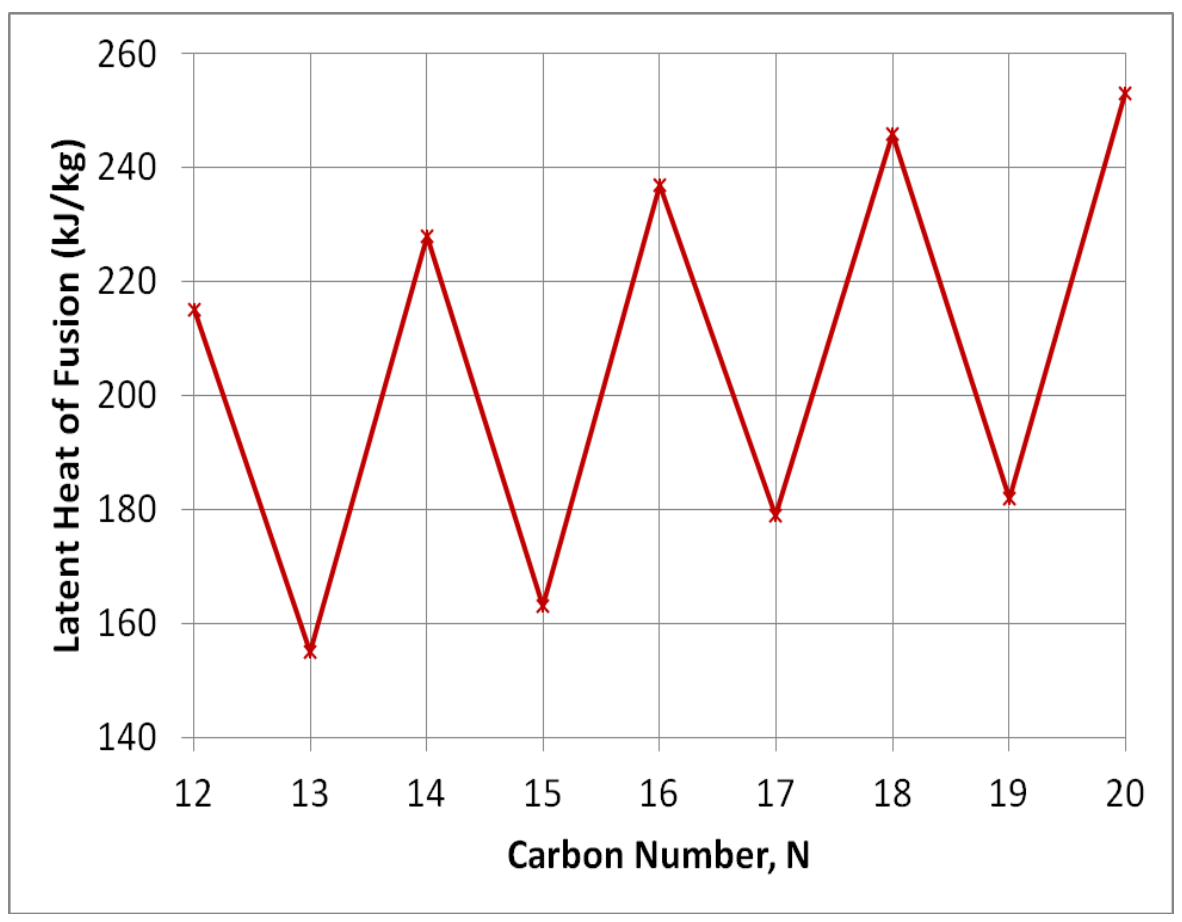

Figure 1. Latent Heat of Fusion of Paraffin $\left(\mathrm{C}_{\mathrm{N}} \mathrm{H}_{2 \mathrm{~N}+2}\right)$. 


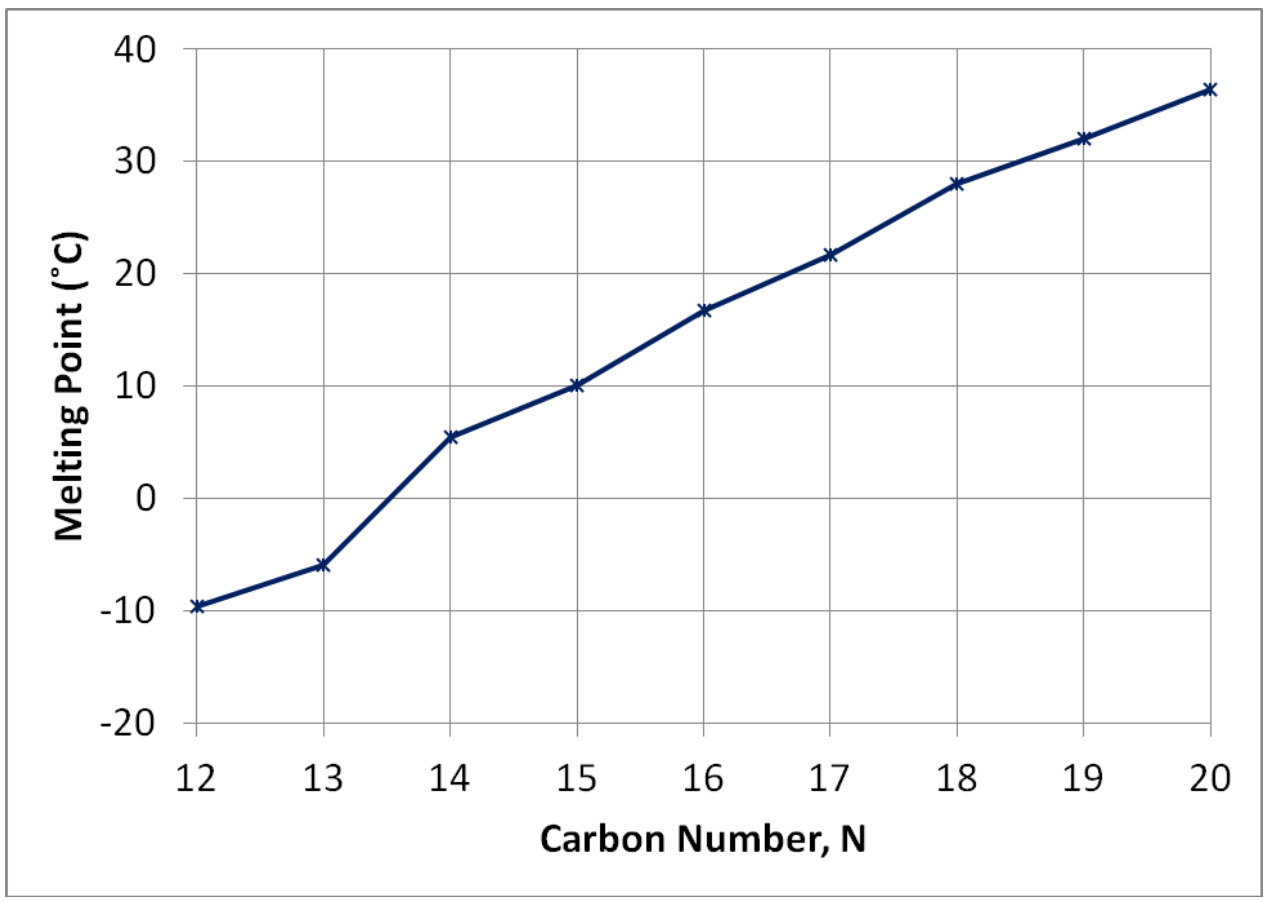

Figure 2. Melting Point of Paraffin $\left(\mathrm{C}_{\mathrm{N}} \mathrm{H}_{2 \mathrm{~N}+2}\right)$.

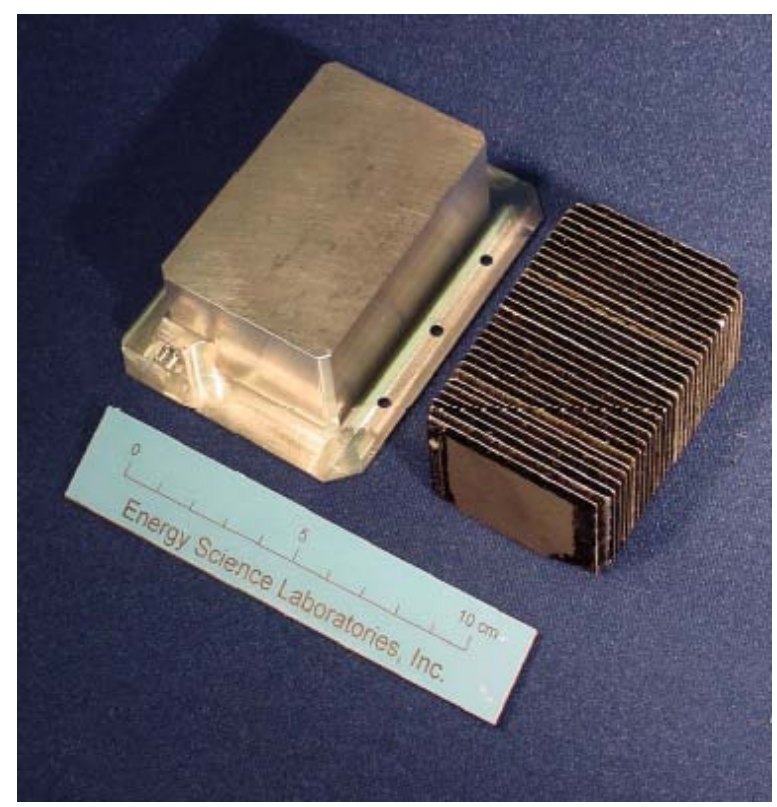

Figure 3. Paraffin Packs Flown on an Instrument in MESSENGER Mission. 


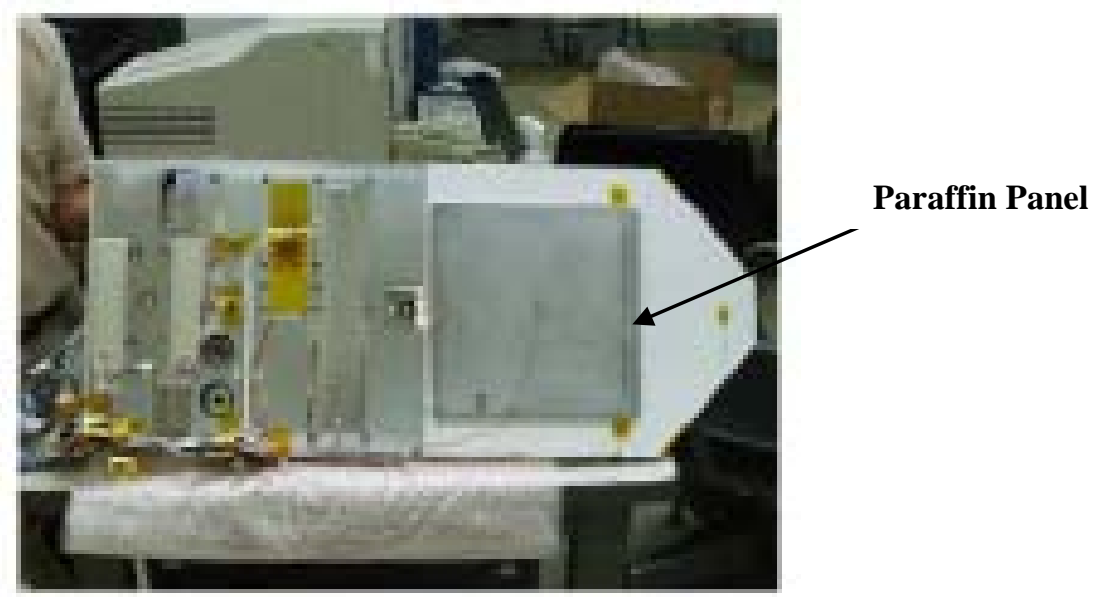

Figure 4. Paraffin Panel Built for Vegetation Canopy Lidar Mission.

\section{Application of Pre-melted Paraffin PCM for ISS Payloads}

An example of payload that utilizes this novel thermal design concept is the Neutron Star Interior Composition Explorer (NICER) proposed by NASA Goddard Space Flight Center for the ISS ELC. Figure 5 shows the locations of ELC. ${ }^{7,8}$ The electronics boxes of NICER are mounted to a thermal sharing plate. The thermal sharing plate is thermally isolated from the instrument optical bench (IOB) bottom plate by titanium flexures. The size of the IOB is $1.18 \mathrm{~m} \times 0.87 \mathrm{~m} \times 0.82 \mathrm{~m}$. The total power dissipation of the electronics boxes is $69 \mathrm{~W}$. Most of the exterior of the electronics boxes has AZW/LA-II low absorptance white paint ${ }^{9}$ to radiate heat to space and minimize the solar or albedo flux absorbed. The detectors are cooled by thermoelectric coolers (TECs). The hot side of the TECs is conductively coupled to a detector plate. The total waste heat rejected by the TECs is $33.6 \mathrm{~W}$. The detector radiator wraps around the IOB and is an integral part of the detector plate. It also has AZW/LA-II low absorptance white paint. The 56 concentrators are mechanically supported by the concentrator plate. Each concentrator aperture has a thin aluminized polyimide film. There are 56 sunshades to prevent sunlight from entering the concentrators. They are thermally isolated from the concentrator plate. The IOB side plates, bottom plate and detector plate are insulated with multi-layer insulation (MLI) blankets. Figure 6 displays the NICER external geometry in the thermal model.

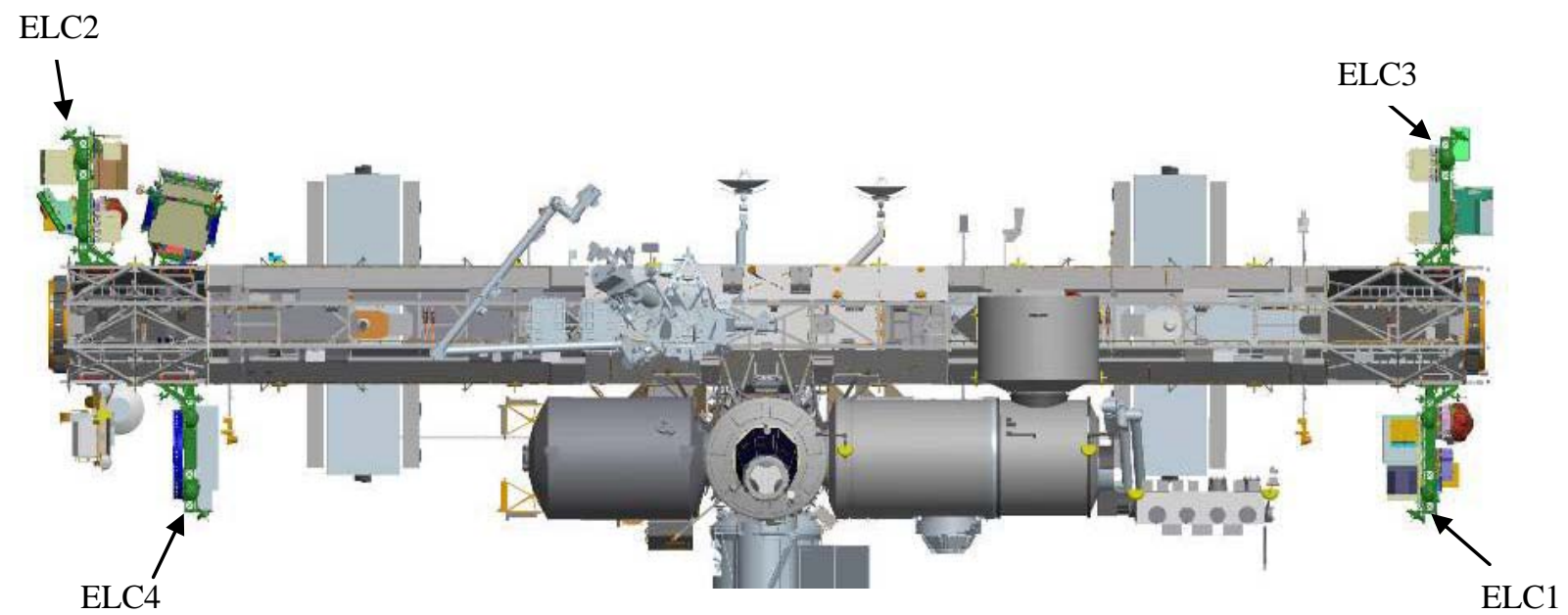

Figure 5. ISS ELC Locations. 


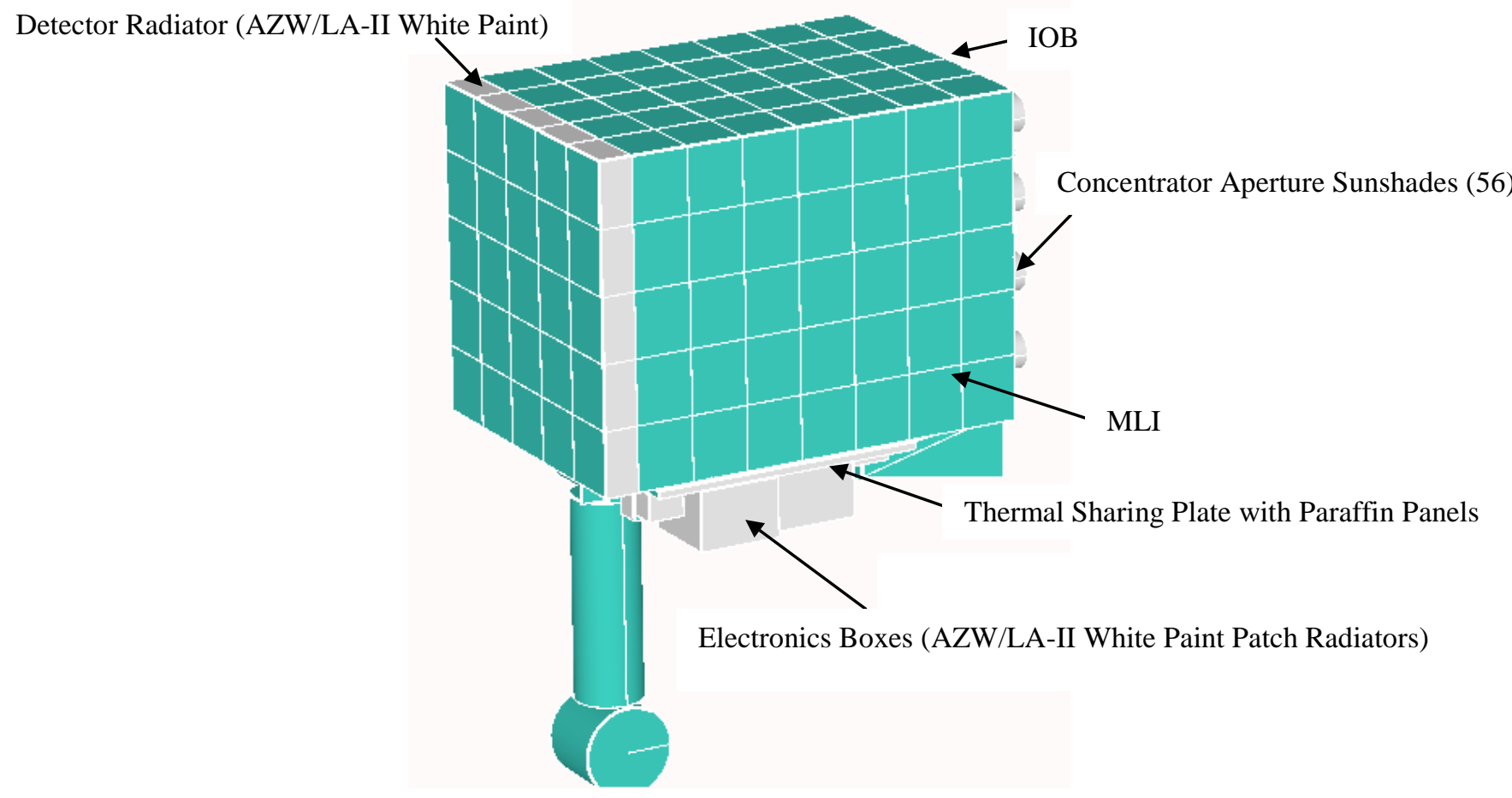

Figure 6. NICER Payload.

During 6 hours without power, the electronics box and detector radiators will continue to radiate heat to space. Also there will be heat leaks through the MLI blankets and through the concentrator thin aluminized polyimide film aperture covers to space.

For the electronics boxes, paraffin PCM panels are attached to the thermal sharing plate which is shown in Fig. 6. A total of four paraffin panels are used. Each panel has $0.5 \mathrm{~kg}$ of paraffin PCM. For the IOB, paraffin PCM panels are attached to the side plates of the IOB. A total of six paraffin panels are used to wrap around the side plates. Figure 7 shows the locations of the paraffin panels. Each panel has $0.38 \mathrm{~kg}$ of paraffin PCM.

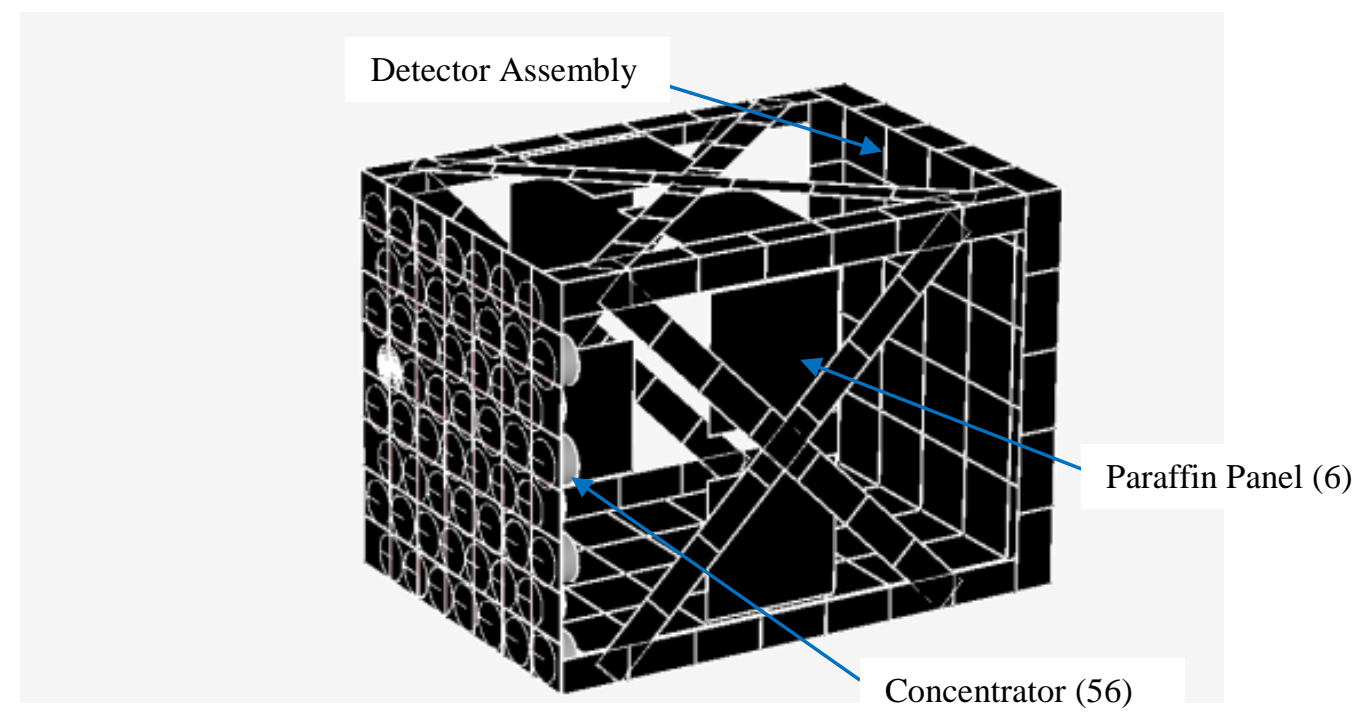

Figure 7. Paraffin Panels on IOB. 
Prior to 6 hours without power, the electronics boxes, detectors and concentrators are warmed to close to hot survival temperature limits. During this warm-up, the paraffin PCM is melted and its temperature is increased to above its melting point. The warm-up mode heaters are attached to the electronics boxes, thermal sharing plate, detector plate and paraffin PCM panels.

Figure 8 shows the temperature predictions for the electronics boxes, detectors and concentrators during 6 hours without power. The temperature predictions have adequate margins.

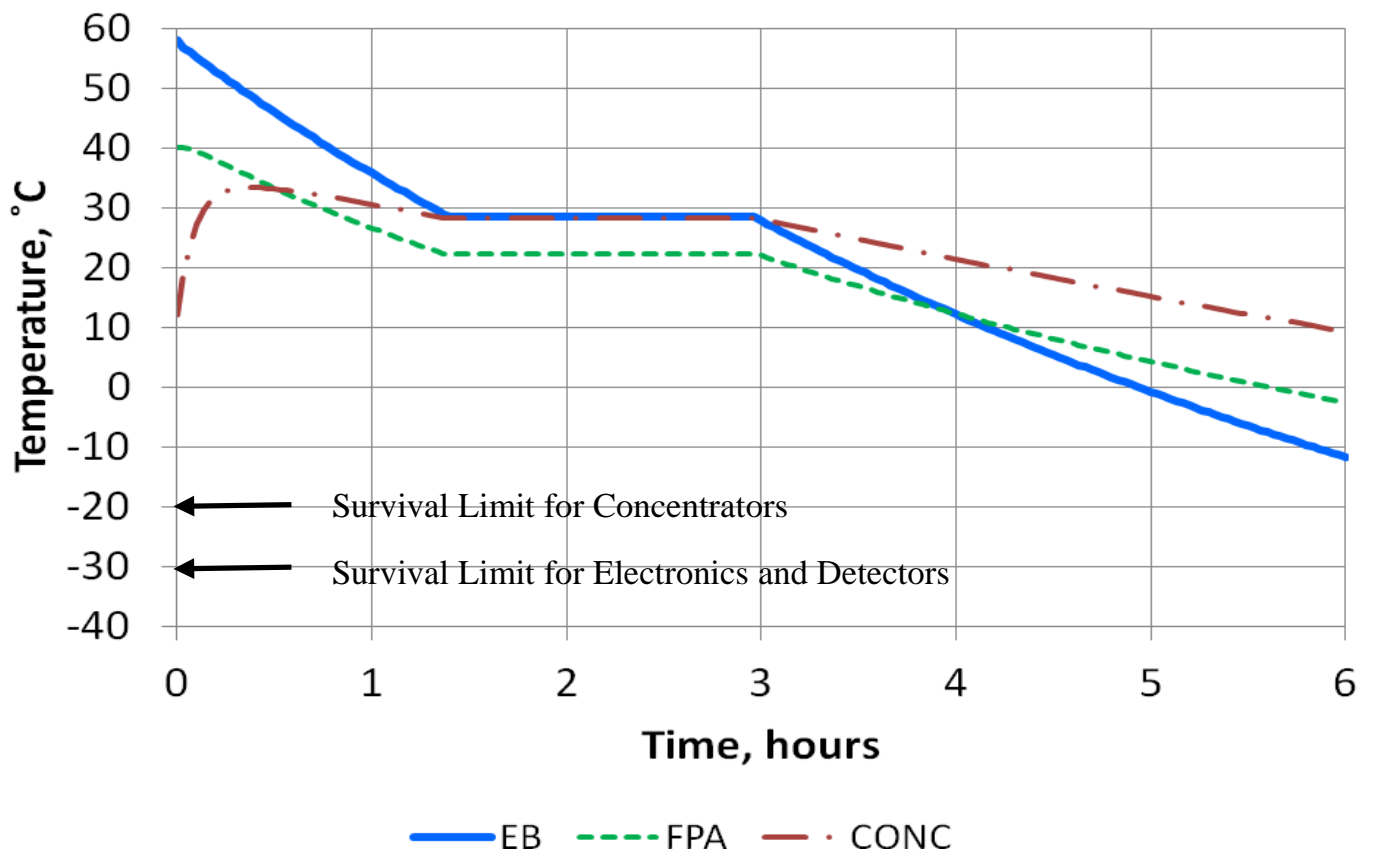

Figure 8. Cooldown of Payload with Paraffin PCM during 6 Hours without Power.

The paraffin PCM panels for the IOB are not only used for thermal control during 6 hours without power, but are also used for thermal control in the operating mode. Operating mode heaters are attached to them and they are painted black. They radiate heat uniformly to the concentrators, concentrator plate, side plates and detector assembly. They also absorb solar heat to maintain the temperature stable so as to minimize thermal-structural distortion. This is another advantage of using PCM.

\section{Application of Pre-melted Paraffin PCM for Free-Flight Interplanetary Probes}

Typically an interplanetary Probe consists of three parts: heat shield/aeroshell, pressure vessel with payload, and aft cover (Fig. 9). ${ }^{2}$ The pressure vessel with payload is always thermally isolated from the heat shield/aeroshell and aft cover. Figure 10 shows the Pioneer Venus Probes and orbiter ${ }^{10}$-- a good example of interplanetary Probe. 


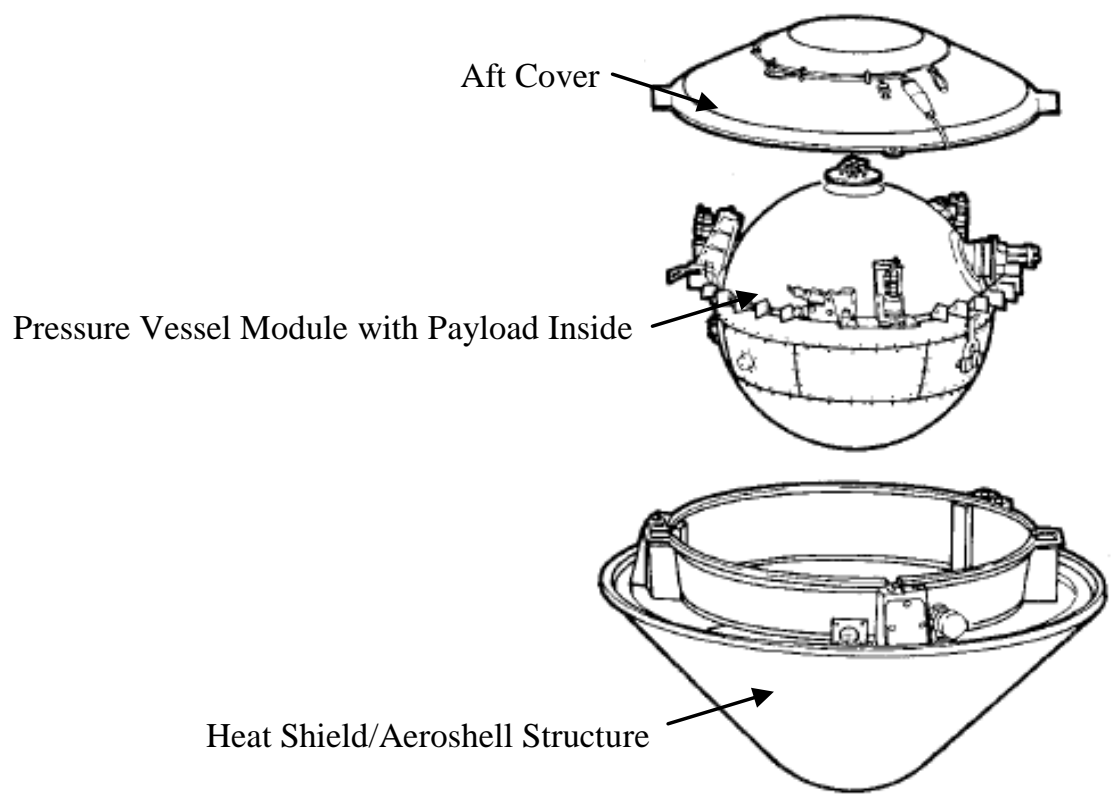

Figure 9. Pioneer Venus Large Probe.

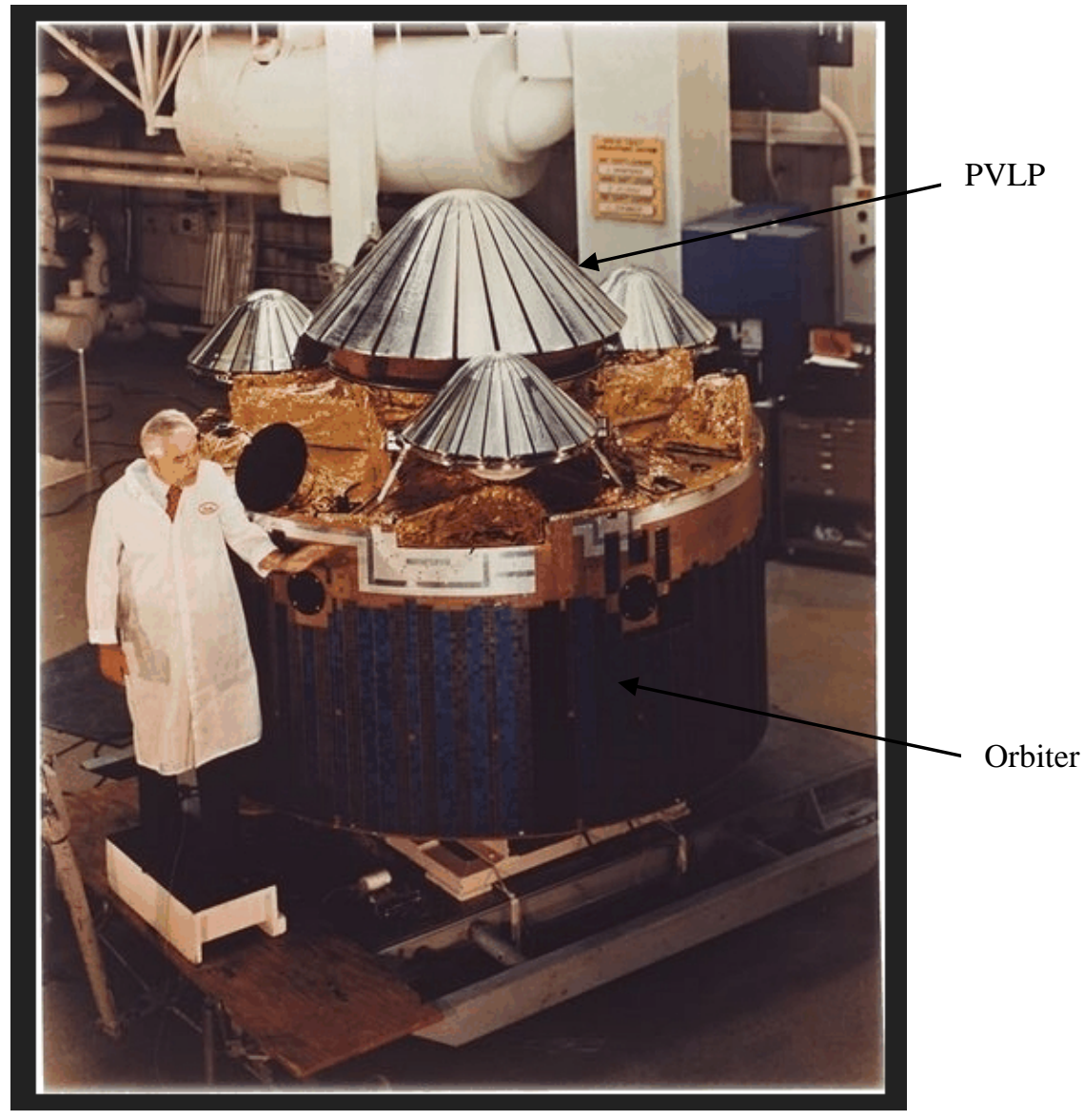

Figure 10. Pioneer Venus Spacecraft. 
While on the orbiter, an interplanetary Probe could be shaded from the sun and continue radiating heat to space. Survival heaters maintain the Probe above the cold survival temperature limits. After separation from the orbiter, the Probe orients to the designed sun angle to receive solar heating. Just after separation, the Probe aeroshell and aft cover temperatures are still at cold survival temperature limits. Because of its thermal inertia, it will take time for solar flux to warm these components up. The worst cold case thermal predictions for the payload are required to be no colder than $0^{\circ} \mathrm{C}$ to assure the thermal design has adequate margins. If PCM is not used, the payload needs to have sufficient payload thermal inertia and to be at a temperature warmer than $0{ }^{\circ} \mathrm{C}$ prior to separation. For example, the PVLP used beryllium equipment shelves to increase the thermal inertia.

The innovative thermal concept in this paper is to use pre-melted paraffin PCM on the payload to store thermal energy prior to separation and when power is available from the orbiter. After separation, the payload continues to lose heat to the aeroshell and aft cover until solar heating is long enough. Figure 11 illustrates heat transfer on an interplanetary Probe shortly after its separation from the orbiter.

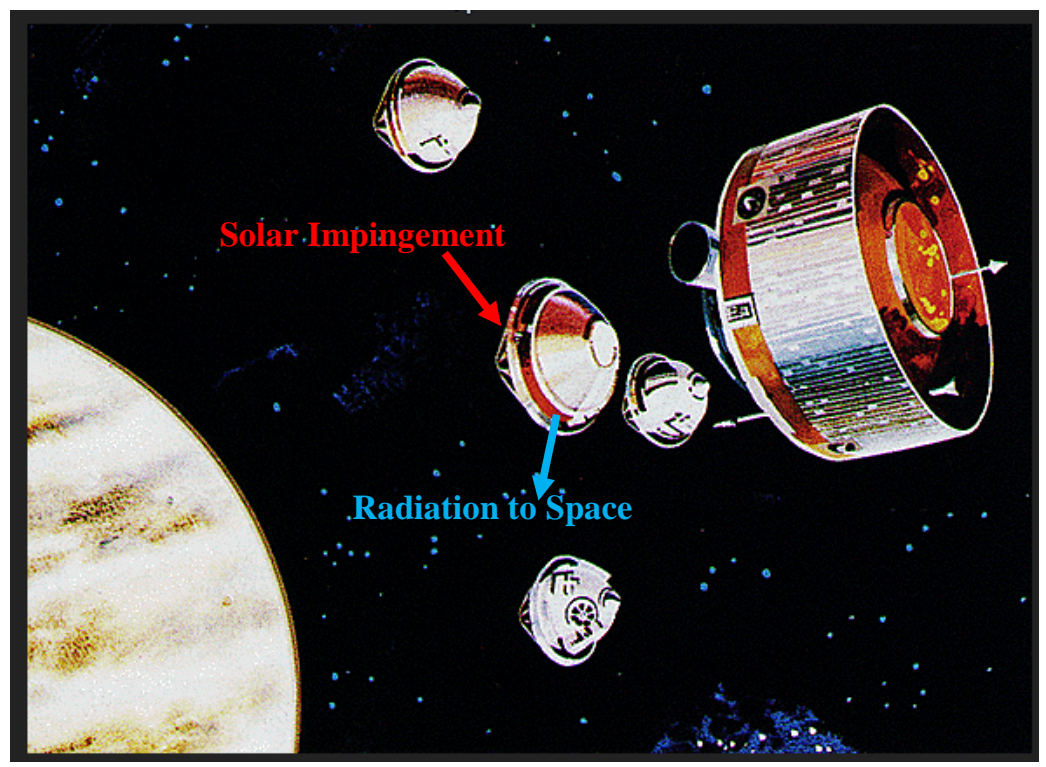

Figure 11. Pioneer Venus Probes Shortly after Separation ${ }^{11}$ - Passive Thermal Control.

After separation from the orbiter, the paraffin PCM gradually changes from liquid to solid and the payload temperature remains unchanged. $\mathrm{N}$-tetradecane, $\mathrm{C}_{14} \mathrm{H}_{30}$, which has a melting point of $5.5^{\circ} \mathrm{C}$ and a high latent heat of fusion per unit mass (226 kJ/kg), is suitable for this application.

Figure 12 presents the temperature predictions for a Probe payload that has a $0.5 \mathrm{~kg}$ of n-tetradecane during its cruise to Venus. This mass of PCM is adequate to prevent the temperature from falling below $0^{\circ} \mathrm{C}$ during the cruise. The solar irradiance is displayed in Fig. $13 .^{2}$ Thermal coatings are tailored to ensure that passive thermal control will provide a payload temperature of $0^{\circ} \mathrm{C}$ to $2^{\circ} \mathrm{C}$ at the end of the cruise. The Probe is $1.5 \mathrm{~m}$ in diameter and the pressure vessel with payload is $0.732 \mathrm{~m}$ in diameter. These are the same as PVLP. 


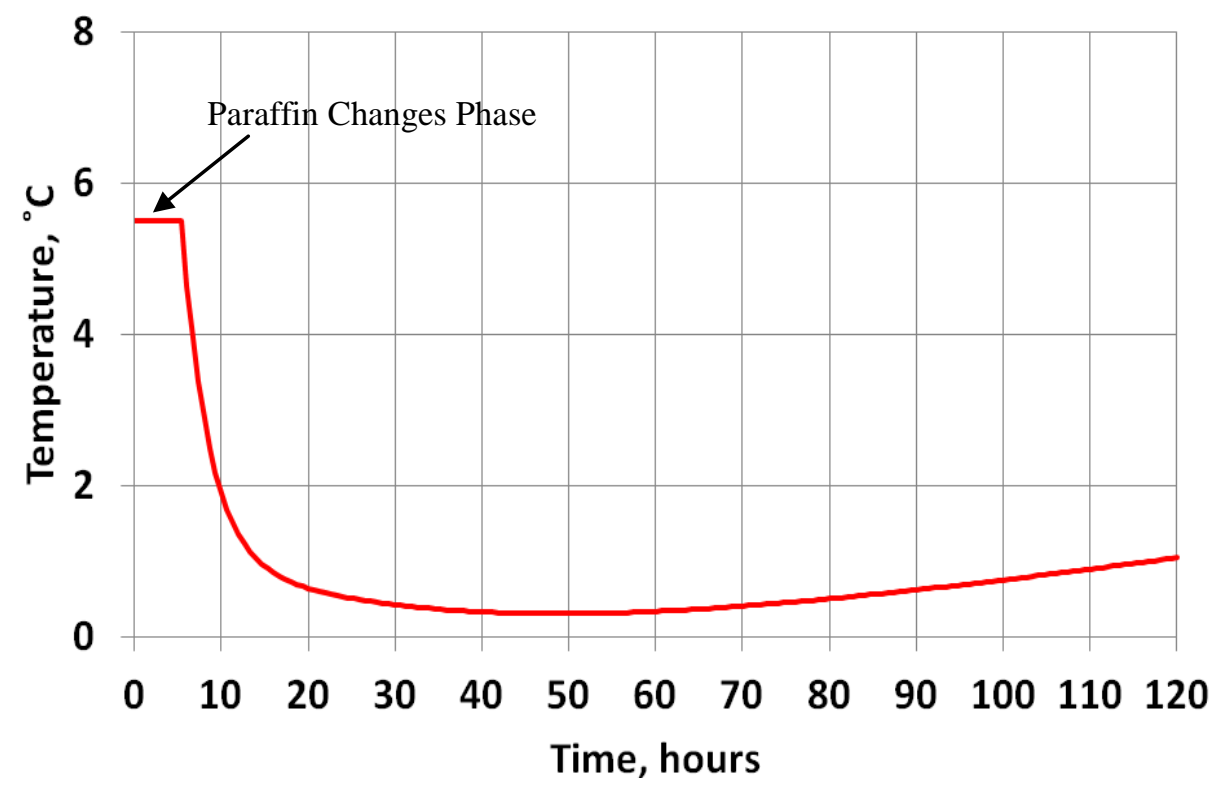

Figure 12. Temperature Predictions for Probe Payload with Paraffin PCM.

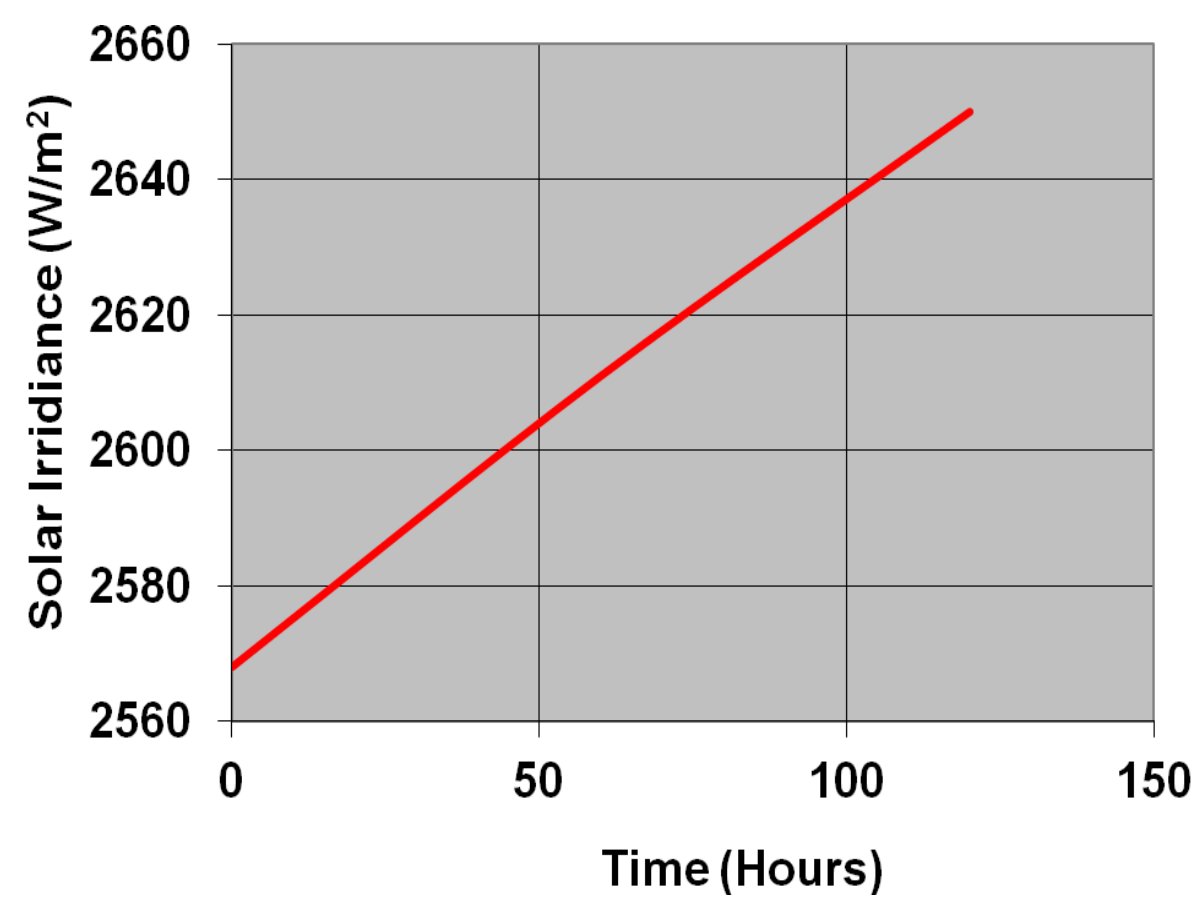

Figure 13. Solar Irridiance during Venus Probe Cruise.

Paraffin PCM is not only used for the Probe thermal control in the cruise phase, but also it absorbs heat from the Venus atmosphere during the Probe descent and landing. During the change from solid to liquid, the payload 
temperature remains at $5.5^{\circ} \mathrm{C}$. If sensible heat storage is used, the payload temperature will continue to rise. Therefore PCM thermal energy storage has a significant advantage over sensible heat storage in this application.

\section{Conclusion}

The innovative thermal design concept presented in this paper utilizes PCM to store thermal energy by melting it before the payload is unpowered. It releases thermal energy to keep the payload warm for several hours after its power is cut off. It has significant advantages over sensible heat storage because its latent heat of fusion per unit mass is high and phase change occurs at a constant temperature.

\section{References}

${ }^{1}$ Hennis, L. A. and Varon, M. N., “Thermal Design and Development of a Planetary Probe: Pioneer Venus Large Probe”, $2^{\text {nd }}$ AIAA/ASME Thermophysics and Heat Transfer Conference”, Palo Alto, CA, May 24-26, 1978.

${ }^{2}$ Hale, D. V., et al., Phase Change Materials Handbook, NASA-CR-61363, Sept. 1971.

${ }^{3}$ Poling, P. E., et al., Perry's Chemical Engineers' Handbook, $8^{\text {th }}$ ed., 2008, McGraw-Hill, New York.

${ }^{4}$ Knowles, T. R., “PCM Thermal Control of Nickel-Hydrogen Batteries”, PL-TR--93-1075, Phillips Laboratory, Kirtland Air Force Base, NM, June 1993.

${ }^{5}$ Knowles, T. R., "Phase Change Composite Thermal Energy Storage”, Energy Science Laboratories, Inc., San Diego, CA, Sept. 2007.

${ }^{6}$ Kedl, R. J., “Wallboard with Latent Heat Storage for Passive Solar Applications”, ORNLTM-11541, Oak Ridge National Laboratory, Oak Ridge, TN, May 1991.

${ }^{7}$ Croonquist, A., “International Space Station: Summary of Platform Specifications”, Nov. 12, 2009, KISS Exoplanet Workshop, JPL/Caltech, Pasadena, CA.

${ }^{8}$ NASA. (2008, August), “Attached Payload Interface Requirements Document - Expedite the PRocessing of Experiments to Space Station (EXPRESS) Logistics Carrier (ELC) Cargo Interface Requirements”, Houston, Texas, United States of America.

${ }^{9}$ AZ Technology, Inc., "Spacecraft Thermal Control and Conductive Paints/Coatings and Services Catalog”, Effective January 2008, Huntsville, AL, p. DS-2a and p. DS-2b.

${ }^{10}$ NASA Ames Research Center (NASA-ARC), “Charlie Hall inspects the Pioneer Venus multiprobe at Hughes Aircraft Co. in Dec. 1976”, December 1976.

11 “Pioneer Venus Bus”, NASA’s HEASARC: Observatories, Goddard Space Flight Center. 